\title{
The Methods of Preparation of Ti-Ni-X Alloys and Their Forming
}

\author{
Radim Kocich, Ivo Szurman and Miroslav Kursa
}

Additional information is available at the end of the chapter

http://dx.doi.org/10.5772/50067

\section{Introduction}

The continuous development of science and technology in all industrial sectors means connecting and usage of a wide range of new knowledge together with implementation of new modern technologies for production of materials with high functional, specific and special properties. Intermetallic compounds TiNi with shape-memory effect are an interesting group of materials. These materials are used in a wide range of industry, such as electronics, robotics, tele-communication and also in medicine and optics. Shape-memory alloys (SMA) are a group of materials characterized by shape-memory effect (SME) and superelasticity (SE), also called pseudoelasticity.

Ti-Ni binary alloys (sometimes called "Nitinol") are probably the best known from this group of materials. Nevertheless, these alloys are not always the most suitable for the particular purpose. This factor is also the reason for seeking optimized variants of these original binary systems. One of the possible solutions is to modify binary alloys by incorporation of one or more chemical elements into the production process. The resulting materials can be summed up in the term Ti-Ni- $(X)$, where $X$ means presence of another element. Although the best memory characteristics are usually achieved for alloys with $\mathrm{Ni}$ content of $49.3 \div 51$ at. \% (Raz \& Sadrnezhaad, 2004), by decreasing the content of one element ( $\mathrm{Ti}$ or $\mathrm{Ni}$ ) to the prejudice of the third element, modified materials are obtained, while preserving some of original characteristics. Among the main characteristics, surpassing SME and SE, mechanical properties, corrosion resistance and related biocompatibility should be mentioned (Van Humbeeck, 2001) or (Duerig et al., 1999). Intermetallic equiatomic compound of nickel and titanium thus remains as the base of modified binary materials. Nevertheless, it should be stated that characteristics of Ti-Ni SMA may be significantly modified otherwise than by the appropriate choice of chemical composition, namely by forming and thermal (thermomechanical) processing. As will be 
indicated later, final properties and products made of SMA are significantly influenced not only by the chosen forming technique, but also their mutual sequence. These factors together with the used technique play a major role in the manufacture of products from SMA.

\section{Method of preparation}

Production of Ni-Ti alloys is mostly done by vacuum melting, whilst various melting procedures are used (electron beam melting, arc melting (Ma \& Wu, 2000) and (Meng, 2001), high frequency vacuum melting in a graphite crucible (Noh, 2001) or (Tsai et al., 1994), plasma melting, etc.). When Ni-Ti alloys are melted, there can be unfavourable effects, especially of gases such as nitrogen or oxygen. Other problems consist in the conditions suitable for crystallization and minimalization of micro- and macro-segregation connected with that. Also, contamination of the material by non-metallic intrusions has to be prevented (Schetky \& Wu, 2005). Due to the formation of titanium carbide and titanium oxide in Ni-Ti, concentration of individual elements changes and thus so does the transformation temperature. Among other problems arising from the melting of $\mathrm{Ni}-\mathrm{Ti}$, there is the formation of low-melting point phase $\mathrm{NiTi}_{2}$, which causes a strong tendency towards hot crack formation.

The basic requirement to metallurgy of these alloys is strict adherence to the chemical composition of the alloy, which is the main condition for obtaining the alloy with the required transformation behaviour. Another condition is obtaining an excellent microstructural homogeneity of the alloy, which is also a condition for functional reliability and guaranteed transformation behaviour. A deviation of about 0.1 at. $\%$ from the required chemical composition usually changes the transformation temperature by as much as $10 \mathrm{~K}$. In Fig. 1a you can see the dependence of temperature of martensitic transformation on the nickel content in the alloy. There is a possibility of attenuation of concentration dependence of the martensitic transformation temperature by alloying with other elements, especially $\mathrm{Cu}, \mathrm{Fe}$, etc.

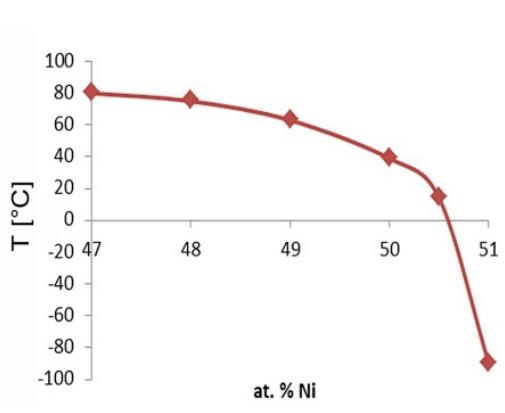

(a)

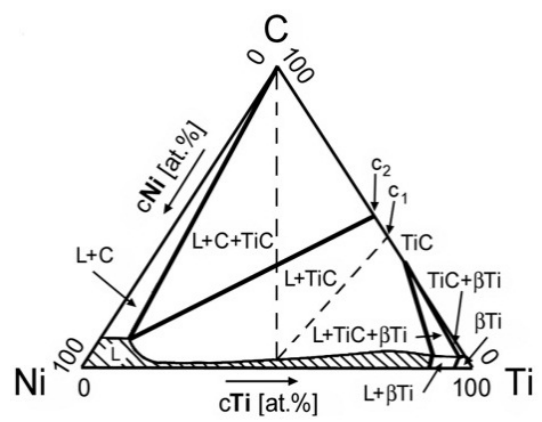

(b)

Figure 1. The dependence of temperature of martensitic transformation (a) Ternary system Ti-Ni-C (b) 
Based on specific requirements of applications such as actuators/sensors, temperature control, fatigue properties, etc., various alloys with the addition of a third element giving a ternary alloy were developed (Otsuka \& Wayman, 1998) or (Zhang et al. 2006).

There is a certain influence of each alloying element on transformation characteristics of the alloy. For example, the addition of $\mathrm{Hf}, \mathrm{Zr}, \mathrm{Au}, \mathrm{Pd}$ and $\mathrm{Pt}$ causes the increase of phase transformation temperatures, while elements such as $\mathrm{Fe}, \mathrm{Co}$, and $\mathrm{V}$ have the opposite effect. Similarly, hysteresis is increased, e.g., by $\mathrm{Fe}$ and $\mathrm{Nb}$, and, on the contrary, decreased by $\mathrm{Cu}$ (Ramajan et al., 2005). As a consequence of alloying by other elements, the transformation sequence is also changed; e.g., at the content of $\mathrm{Cu}$ below $7.7 \%$ one-stage phase transformation $\mathrm{B} 2 \rightarrow{\mathrm{B} 19^{\prime}}^{\prime}$ occurs (similarly as in a binary alloy). If the content of $\mathrm{Cu}$ exceeds $7.7 \%$, two-steps transformation $\mathrm{B} 2 \rightarrow \mathrm{B} 19 \rightarrow \mathrm{B} 19^{\prime}$ takes phase (Tang et al., 2000). The alloy properties may also be significantly influenced by alloy impurities from the production process, forming, heat treatment, etc. As it was already stated, there could be an important role of gases $\left(\mathrm{O}_{2}, \mathrm{~N}_{2}, \mathrm{H}_{2}\right)$ and carbon. In the resulting structure intrusions of the type $\mathrm{Ti}_{4} \mathrm{Ni}_{2} \mathrm{O}_{x}, \mathrm{TiO}_{2}$ etc. connected with the decrease of $\mathrm{Ti}$ content in the matrix can be observed. There is significant influence of these composition changes on transformation characteristics of the alloy.

Typical superelastic nitinols contain ca. 350-500 ppm of oxygen and 100 $\div 500$ ppm of carbon. The metallurgical purity (grain structure, presence of impurities etc.), of course, greatly depends on the preparation process. Ni-Ti alloys can be called high-purity alloys if they contain $<100 \mathrm{ppm}$ of oxygen and $<20 \mathrm{ppm}$ of carbon. These alloys are prepared in vacuum induction furnaces in graphite crucibles with the subsequent repeated re-melting in vacuum arc furnaces (Graham et al., 2004).

\subsection{VIM - Vacuum induction melting}

As has already been stated, VIM is one of the production processes used for the preparation of TiNi alloys. The technology of vacuum induction melting in graphite crucibles represents the existing key preparation method. Chemical homogeneity within this technology can be achieved by appropriate power control (and stirring of liquid alloy connected with that). When using this technology, the quality of the prepared alloy will strongly depend on the material of the crucible. Usually the mentioned graphite crucible is recommended - where the oxygen content can be neglected; nevertheless, carbon absorption must be considered here (there is a significant influence of carbon on microstructural characteristics and transformation behaviour). During the preparation of the material in a graphite crucible it was also found (Frenzel et al., 2004) that in the case of using Ni-pellets and Ti bars/disks the appropriate arrangement of the material in the crucible was important. The authors of this study have shown that although the inner surface of the crucible was covered with Ti disks, the content of carbon in the produced alloy was lower in comparison with the case of random arrangement of the charge. This phenomenon is caused by formation of a $\mathrm{TiC}$ layer, which acts as a diffusion barrier. It was also found that the carbon content strongly depends on temperature and time of dwell of the melt in the crucible. For this reason, a more 
intensive investigation of these effects was carried out (Zhang et al., 2006). It was established that with increasing time of dwell of the melt in the crucible the melt gets enriched in carbon.

In Fig. 1b (Du \& Schuster, 1998) it is possible to see more detailed information on the isothermal section (at $1500^{\circ} \mathrm{C}$-temperature recommended for melting of $\mathrm{Ni}$-Ti based alloys) of the Ni-Ti-C ternary system. The composition in this system is given in atomic \%. It is shown that there exists a single-phase region of liquids, extends from the area of pure $\mathrm{Ni}$ to the area of pure Ti. There exists only a narrow two-phase area $\mathrm{L}+\beta-\mathrm{Ti}$ which separates the area of melted material from the $\beta$-Ti phase. The diagram also shows that the melted material dissolves a certain amount of carbon (this dissolution is limited). Elementary melted $\mathrm{Ti}$ and $\mathrm{C}$ cannot coexist in equilibrium state, due to this reason a TiC carbidic phase is created. The diagram in Figure $1 \mathrm{~b}$ also predicts the existence of three phases in thermodynamic equilibrium: pure carbon, $\mathrm{TiC}$ carbidic phase and melted Ni-Ti depleted by Ti. The reactions between the melt will result in a melted material with higher carbon content and certain amount of $\mathrm{TiC}$. In practice we cannot expect this equilibrium.

When the molten Ni-Ti enters into contact with the graphite of the crucible, inter-diffusion causes a growth of the $\mathrm{TiC}$ layer and the contents of carbon in the melted alloy grows. This process includes the diffusion of carbon through a thin layer of $\mathrm{TiC}$ which grows on the boundary between $\mathrm{TiC} /$ melted Ni-Ti. On the boundary between graphite / $\mathrm{TiC}$ and the boundary of $\mathrm{TiC} /$ melted material we expect local thermodynamic equilibriums. If using a pure (unused, new) crucible for preparing the alloy, the first prepared ingot will have a higher content of carbon than the next one. This fact is in accordance with the creation of the above-listed $\mathrm{TiC}$ diffusion barrier. It is also recommended to perform rinse-melting before melting alloys in an unused crucible.

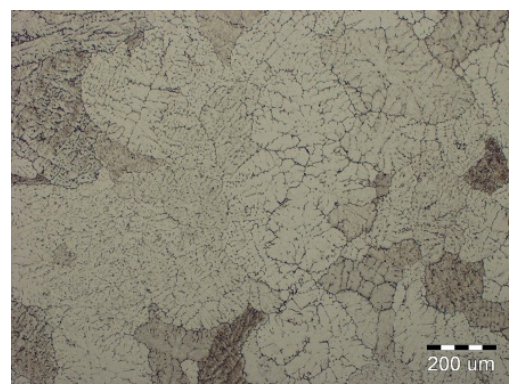

(a)

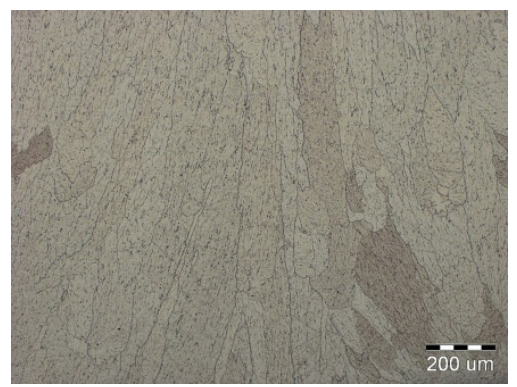

(b)

Figure 2. As cast state of alloy: Ni50.6-Ti(at.\%) (a), Ni46-Ti50-Co4 (b)

In order to define the exact influence of the used technique, an experimental study (Szurman \& Kursa, 2010) with the aim of monitoring the influence of the preparation process on microstructural characteristics of $\mathrm{Ni}-\mathrm{Ti}-(\mathrm{X})$ alloys was performed. The examples of microstructures of Ni50.6-Ti (at. \%) and Ni46-Ti50-Co4 cast alloys are presented in Figs. $2 \mathrm{a}$ and $2 \mathrm{~b}$. As a consequence of the preparation of alloys in a graphite crucible, TiC type 
carbide phases are visible in the alloys' microstructure. A TEM image of the TiC phase (Fig. 3a) with the appropriate diffraction is presented in Fig. 3b. Similarly as with carbides, oxide phases can also be seen in microstructures of Ni-Ti alloys. A specific example is presented in Figs. $4 \mathrm{a}, \mathrm{b}$ where particles of $\mathrm{Ti}_{4} \mathrm{Ni}_{2} \mathrm{O}$ can be seen.

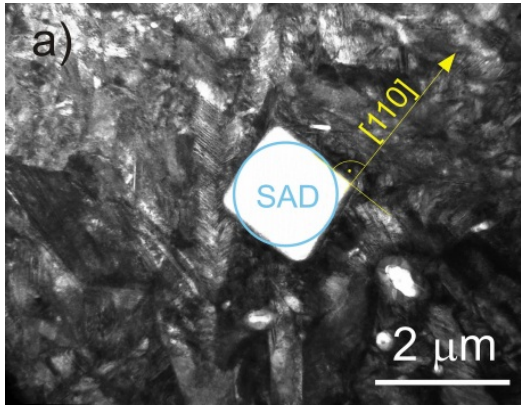

(a)

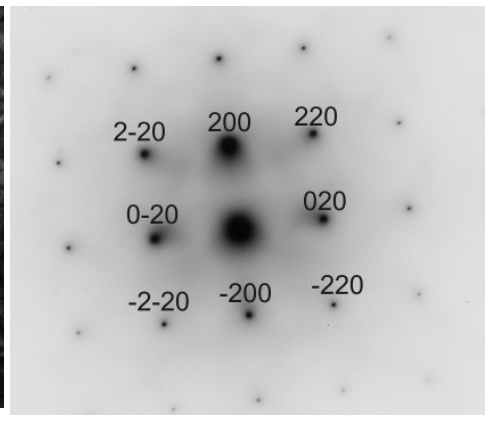

(b)

Figure 3. TiC phase: TEM image (a), corresponding diffraction pattern (b)

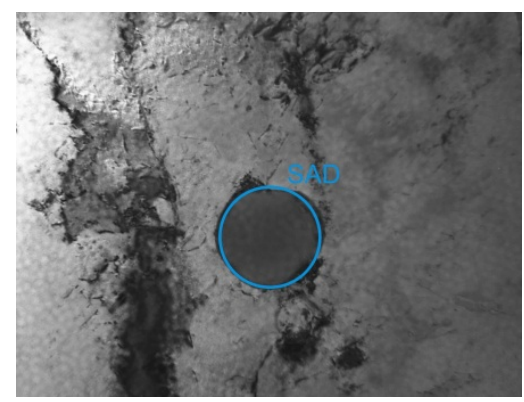

(a)

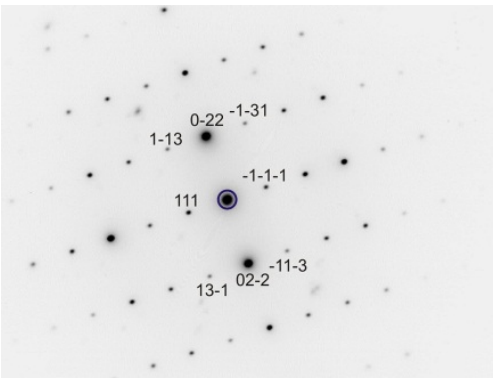

(b)

Figure 4. Particle of $\mathrm{Ti}_{4} \mathrm{Ni}_{2} \mathrm{O}(\mathrm{a})$, corresponding diffraction pattern (b)

\subsection{Plasma melting - Plasma furnace with horizontal crystallizer}

This is another possible preparation process; there are, however, serious drawbacks. During this process, input elemental metals are placed in the copper water-cooled crystallizer. The crystallizer is carried by the screw below the plasma burner. Argon is used as a plasma-forming gas. For the melting as such it is necessary to use the cleanest available argon due to high affinity of titanium to oxygen. The plasma temperature during this process reaches $6500 \mathrm{~K}$ (Dembovský, 1985) and (Pacholek et al., 2003). The advantage of this process can be seen in the prevention of contamination of melted material by graphite from used electrodes (crucibles); high concentration of energy, high plasma flow velocity and very quick heat transfer on the heated material ensure high speed of melting. Disadvantages of plasma furnaces in comparison with vacuum induction furnaces include lower degassing of the melted metal, which depends on purity 
of the used argon. The key disadvantage of this process consists in insufficient homogeneity of the prepared alloy.

The development of plasma furnaces takes place in two main directions. Melting units working on the similar principle as common arc furnaces can be added to the first type of plasma furnaces. There is only one difference - that instead of electrodes, plasma burners are used and the furnace used to be equipped with special soil electrode carrying the current into the charge. The working space of furnaces is often designed to be vacuum-tight, which enables maintaining an ideal inert atmosphere. This type of furnace can be equipped with a relatively simple device for electromagnetic stirring of liquid metal.

The second furnace type is plasma furnaces with water-cooled metal crystallizers. As to the arrangement, the concept of these furnaces is similar to electronic furnaces, with the difference that instead of electron guns plasma burners are used and the furnaces mostly work with the pressure of an inert gas varying around $10^{5} \mathrm{~Pa}$. Exceptionally, there are furnaces with overpressure. In metallurgy, so-called low-temperature plasma in particular is considered, which is a system comprising a mixture of neutral particles with the prevailing number of electrons and positive ions with temperatures in orders of $10^{3}$ to $10^{4} \mathrm{~K}$. The temperature of $10^{5} \mathrm{~K}$ can be considered as the temperature of totally ionized plasma (Dembovský, 1978).

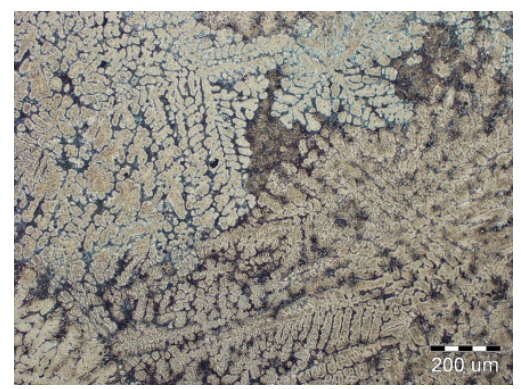

Figure 5. Microstructure of alloy Ni49.5-Ti25.5-Zr10-Nb15 (at. \%), plasma

Specific experiments with melting of selected alloys Ti-Ni- $(X)$ are described, e.g., in studies (Szurman \& Kursa, 2009). Using this technique, ingots with the weight of 200-1000 g were prepared. In Fig. 5 you can see microstructure of alloy after plasma melting. As you can see, the microstructure of the alloy is highly inhomogeneous. This problem is caused by very high temperature gradients during melting. At the top of the ingot the alloy is heated to a high temperature. On the other hand, the part of the ingot which is in contact with the crystallizer is intensively cooled.

\subsection{VAR - Vacuum Arc Melting}

VAR technology is widely used to increase metallurgical purity of alloys prepared using standard procedures, e.g., in vacuum induction furnaces. This procedure is also known as 
"consumable electrodes". Direct current is used for the formation of arc between the electrode (melted material) and a water-cooled copper crucible/crystallizer. As a consequence, the electrode tip is melted and a new ingot is formed within the water-cooled crucible. The melt during the arc vacuum melting therefore is not in contact with the graphite crucible (as it is in the case of the VIM technique with a graphite crucible/mould), thus a "more pure" product can be obtained using this method. The carbon content usually does not exceed 200 ppm (Dautovich \& Purdy, 1965) or (Wu, 2001). For this technique a very high vacuum is required.

Nevertheless, there are also drawbacks of this technique - small volume of the alloy and low convection in the melt which may cause inhomogeneity of ingots. That is also the reason why this procedure is usually repeated several times. Often the VIM+VAR process is applied for the preparation of Ti-Ni- $(\mathrm{X})$ alloys. VAR technology is also preferred for preparation of experimental material for basic research of Ti-Ni- $(\mathrm{X})$ alloys. For example, the study (Choi et al., 2005) describes the preparation of experimental Ni-Ti alloys alloyed by Fe. In this study, the ingot prepared using this method is homogenized at $1273 \mathrm{~K}$ for 24 hours. In another study (Sakuma et al., 2003) heat treatment at $1223 \mathrm{~K}$ for 1 hour after the preparation of the material using this method is proposed. The specific regime is also mentioned in the study (Jung et al., 2003) where heating at $1100^{\circ} \mathrm{C}$ for $100 \mathrm{~h}$ was used.

\subsection{EBM - Electron Beam Melting (Vertical Zone Melting)}

Crucible-free zone melting - or the floating zone process known as the FZ method represents another specific preparation method. The formation of a narrow melted zone is performed using electron heating. The melting takes place in a vacuum, and values of $10^{-}$ ${ }^{2} \mathrm{~Pa}$ are reached in this technology compared to $10 \mathrm{~Pa}$ in VIM technology. Using the method of electron zone melting with suitable oriented nuclei, even monocrystals of many highmelting metals $-\mathrm{W}, \mathrm{Mo}, \mathrm{Ta}, \mathrm{Nb}, \mathrm{V}, \mathrm{Zr}$, Ti, $\mathrm{Re}$ - can be prepared. The zone is maintained in the floating condition mainly by forces of surface tension. The zone stability depends on gravitation, surface tension and density of the melt, on material composition and also on direction of zone movement. To maintain the stability of the zone, an outer magnetic field with so-called supporting frequency is used (Kuchař \& Drápala, 2000). A circular shape ingot prepared in a vacuum induction furnace is used in this case as input material. There is no risk of other contamination of the material with carbon in this technology (there is no crucible). Carbon contents are usually lower than in the case of the alloy preparation using VIM technology. Contents of gases are usually low as well because of using a high vacuum. The contamination with gases thus depends only on the quality of an input casting and tightness of the vacuum system. The disadvantage of this technology is the control of chemical composition - evaporation of some elements can be expected here during melting. Another drawback is the rather small volume of the prepared material; therefore this technology is not suitable for commercial use (Ramaiah et al., 2005).

Rather integrated results regarding (un)suitability of various methods of preparation are presented, e.g., in a recent study (Szurman \& Kursa, 2009). The aim was an intercomparison 
of techniques selected for the preparation of Ti-Ni- $(X)$ alloys from the point of view of the microstructure and gas contents in the material. Also in this situation a distinct decrease of gas contents after the preparation was observed here. The specific microstructure of the prepared alloy Ni50,6-Ti (at.\%) is presented in Fig. 6.

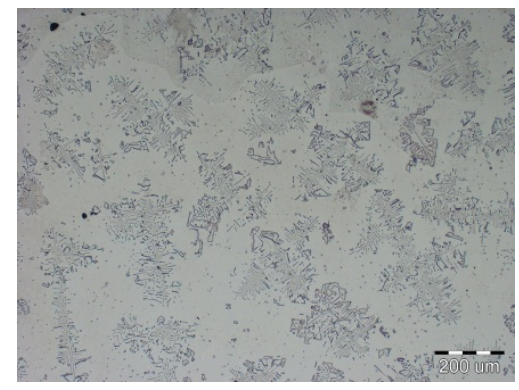

Figure 6. Microstructure of alloy Ni50.6-Ti (at. \%), EBM

\subsection{Preparation of alloys using powder metallurgy}

Powder metallurgy is an important and suitable method for the production of the mentioned alloys. Methods of atomization were developed for preparation of powder metals with precise control of composition. However, the biggest problem with these alloys is oxygen and carbon content. The content of oxygen can be up to $3000 \mathrm{ppm}$, but it can be decreased by careful treatment to 1500 ppm (Schetky \& Wu, 2005). It is well known that with increasing content of impurities (especially oxygen and carbon), transformation temperatures are decreased and a brittle secondary phase is formed (Mentz et al., 2008). Subsequently, the composition of NiTi matrix (depletion by Ti) is significantly influenced by oxide and carbide intrusions and thus can cause degradation of functional and mechanical properties, which was also confirmed, e.g., in the study (Mentz et al., 2006). Other methods are hydridation, pulverization and mechanical alloying $(\mathrm{Wu}, 2002)$.

The method for preparation of Ni-Ti alloy using powder metallurgy is described in the study (Mentz et al., 2008). At first, the alloy was prepared by authors using a classical VIM melting from high-purity input raw materials, then atomization with $6 \mathrm{~N}$ argon followed. The obtained powders were sealed into evacuated capsules made from stainless steel and then compacted using the HIP method. It was also found that each technological step is accompanied by increased content of impurities (oxygen and nitrogen). In the study (Bertheville \& Bidaux, 2005) the authors performed the preparation of Ti-rich Ni-Ti alloy from elementary powders - $\mathrm{Ni}$ and $\mathrm{TiH}_{2}$. In another study (Zhu et al., 2005), preparation of $\mathrm{Ni}-\mathrm{Ti}$ alloy by sintering in argon from elementary $\mathrm{Ni}$ and $\mathrm{Ti}$ powders is described. Another method of preparation is then described in the study (Mousavi et al., 2008), where a method of mechanical alloying is described. The Ni-Ti alloy was prepared from elementary powders in a planetary ball mill under atmosphere of Ar. During sintering of $\mathrm{Ni}$ and $\mathrm{Ti}$, a significantly exothermic reaction takes place so that the heat generated during the process is used for the formation of the intermetallic compound TiNi. 
Elemental powders can also be sintered using "combustion" synthesis or explosion. In the first case, a laser can be used as an external energy source (Bertolino et al., 2003). As for explosive sintering, the reaction takes place after explosion during the temperature rise. Another method is based on the passage of an electric current of suitable value under optimal voltage. It was found that the optimal current density is $2822-5290 \mathrm{kA} \cdot \mathrm{m}^{-2}$. The observed sintering times were within the range $5 \div 40 \mathrm{~min}$ (Locci et al., 2003). Ni-Ti materials prepared from powder metals are very porous and contain other intermetallic compounds such as $\mathrm{Ti}_{2} \mathrm{Ni}$ and $\mathrm{Ni}_{3} \mathrm{Ti}$.

\section{Forming of SMA}

Apart from the already mentioned influence of the selected preparation method of SMA, final properties and behaviour of SMA will be also determined by next processing including heat treatment. This means not only the chosen method of forming, but also a sequence of given forming operations. Also the influence of applied regimes of heat treatment should be considered. All the mentioned factors have their own partial effect in formation of final properties of SMA-based materials. With admixture elements, such as $\mathrm{Cu}$ contained in binary NiTi alloys, martensitic transformations are considerably shifted and at the same time also mechanical or thermomechanical characteristics of SMA are changed, as can be seen, e.g., in the study (Liu, 2003). Hand-in-hand with forming or heat processing, strengthening and healing processes are also important. Several studies are known, e.g. (Gili et al., 2004) or (Morgiel et al., 2002), which confirm the importance of chemical composition ( $\mathrm{Cu}$ content) during dynamic recrystallization, esp. near borders of grains. On the other hand, other studies (Nam et al., 1990) bring information on formability of SMA when Ni was substituted by $\mathrm{Cu}$. If $\mathrm{Ni}$ is substituted by $\mathrm{Cu}$ up to the content of ca. $10 \%$ (i.e. binary $\mathrm{NiTi}$ alloy will be modified to $\mathrm{Ti}-40 \mathrm{Ni}-10 \mathrm{Cu}$ ), then the phase transformation will take place in two steps and these alloys will be much more deformable in the martensitic state than original NiTi alloys. Despite these findings it is still valid that when $\mathrm{Cu}$ content exceeds the limit 10 at.\%, Ni-Ti-Cu alloys exhibit a rather low formability.

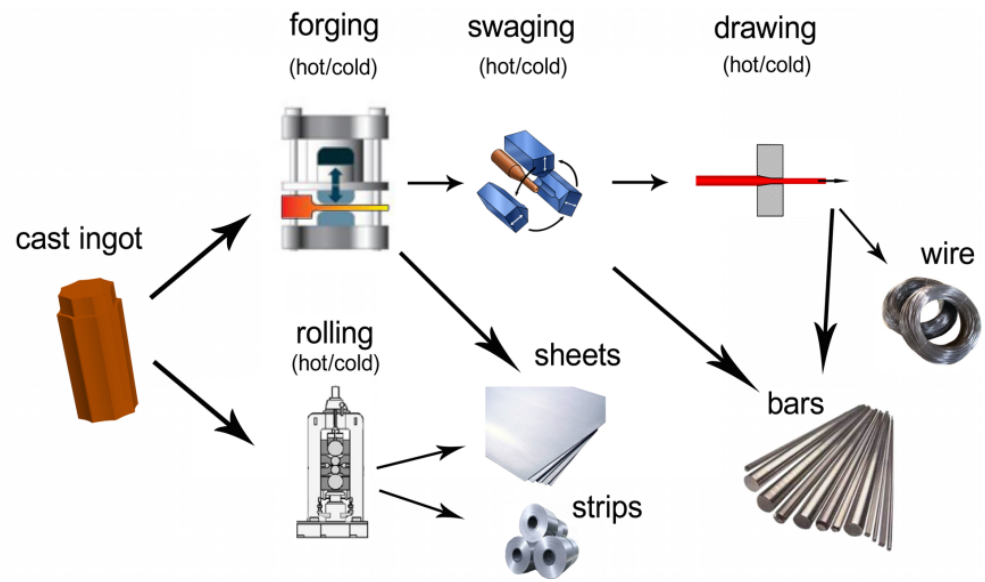

Figure 7. Scheme of basic forming operations used for plastic deformation of SMA 
The chosen method of forming together with the method of heat processing is directly proportional to achieved characteristics. Although SMA are mostly used in the form of thin belts, wires or pipes (Kursa et al., 2005), all these products are produced by forming from original cast ingots. Ingots in the cast state are characterized by a very low formability and usually only a small or no memory or superelastic effect. With subsequent hot or cold forming these properties are modified. In Fig. 7 you can see a scheme of basic distribution of forming operations which are usually used for plastic deformation of SMA. Similarly as in other materials, the main aim of hot forming is to change the dimensions and shape of cast ingot, together with modification of its unfavourable microstructure. For the "destruction" of the original dendritic structure, some deformation depending on the cross section of the treated ingot should be applied. It is not unusual for the real size of the applied strain which will provide the required changes to reach values of around $90 \%$. High degrees of deformation performed as hot forming are often also conditioned by requirements arising from the consecutive cold forming, during which such significant reductions of cross section cannot be realized (Ramaiah et al., 2005). Nevertheless, especially recently, when an explosion of unconventional forming techniques occurred, it can be said that intensities of applied strain can reach, and in practice do reach, much higher values than $100 \%$. It should be stated that in these cases it is a shearing deformation where no significant changes in cross section occur. The main aim of these unconventional forming techniques is to achieve structural modification with the effort to deform materials at temperatures as low as possible.

The conventional treatment (forming) of SMA is usually divided into more stages. A frequent sequence of individual operations consists in melting, casting, hot swaging, cold rolling and drawing. Especially during cold forming techniques it is common to insert heat treatment between partial operations. So it is obvious that the transformation behaviour of a particular alloy will be influenced by each of these mentioned operations. In the first stages (melting, casting), there is an already mentioned factor of chemical composition. However, the production process itself can be performed in several various ways with different influence on the studied characteristics, which is documented by a high number of performed studies (Frenzel et al. 2004 and Zhang et al., 2005 and Frenzel et al., 2007a). Regardless of the chosen technique of melting, increased attention should be paid in all techniques to minimization of additional elements, especially oxygen and carbon. These elements have negative influence on the memory effect and also on the brittleness of the particular alloy, which is not without perceptible consequences, especially during the stage of forming.

During alloy forming, which is usually performed in the temperature range $300 \div 900^{\circ} \mathrm{C}$, in addition to the present admixtures, defects in the crystal lattice also begin to come to light. To be more specific, both point defects and changes in the dislocation density begin to activate, which will significantly influence healing and precipitation processes (Frenzel et al., 2007b) or (Kocich et al., 2007). In binary NiTi alloys at around temperatures of $400^{\circ} \mathrm{C}$ the softening process begins, while at temperatures of $900^{\circ} \mathrm{C}$ formability (elongation) of alloys determined by tensile tests can exceed $100 \%$. Although SMA at these temperatures exhibit 
relatively good formability, during alloy forming some cracks may appear, especially near the edges. Usually bars or plate slabs are prepared by forming (forging, rolling). The deformation behaviour of SMA can probably be considered optimal in the temperature range near $800^{\circ} \mathrm{C}$. Just these temperatures lie in the range where the alloys are workable and at the same time oxidation of their surface is not as massive as at higher temperatures $(\mathrm{Wu}$, 2001). If forming temperatures are too high, the mentioned oxidation takes place and with increasing temperature the degradation of the material increases as well. The consequence of these processes is formation of very stable oxide layers which are often a part of the surface and cause destruction of the material due to the formation of cracks. When SMA is heated to the temperature $900^{\circ} \mathrm{C}$, the alloy tends to be brittle because of occurrence of the $\mathrm{Ti}_{4} \mathrm{Ni}_{2} \mathrm{O}$ phase.

After hot forming of alloys, heat treatment is very often applied. The influence of annealing temperatures or cooling rate after annealing is already known very well; more detailed information on partial modes can be found, e.g., in the study (Standring et al., 1980). Generally it can be said that longer annealing times cause higher Af temperatures (austenite finish). It is known that an increase of transformation temperatures ( $\left.A_{s}, A_{f}\right)$ depends on the technology used for the preparation (machining) of SMA and is caused by temperatureinduced stresses and defects. High $\mathrm{Ms}_{s}$ temperature is attributed to incomplete transformation during heating. The mentioned heat treatment is used for optimization of physical and mechanical properties together with maximization of shape memory effect and pseudo-plastic behaviour. The main reason for performed heat treatment after forming is thus modification of transformation temperatures for specific applications. When compared to the relatively wide interval of forming temperatures, the range for annealing temperatures is considerably narrower $\left(300^{\circ}-525^{\circ} \mathrm{C}\right)$. The times used for annealing are usually in the order of minutes (5-30). Relatively stable resulting transformation temperatures are documented for annealing at temperatures of about $500^{\circ} \mathrm{C}$ and times shorter than 10 minutes (Liu et al., 2008). With increasing time of annealing Af temperature increases and stress decreases. Increase of $A_{f}$ is usually accompanied by depletion of the $\mathrm{NiTi}$ matrix by $\mathrm{Ni}$, which is precipitated in the form of precipitates.

\subsection{Swaging}

As has already been mentioned before, one of the first forming procedures used for plastic deformation of cast ingot is swaging. Swaging is a forming process characterized by a very high rate of deformation (i.e. potential possibilities for the production are 4-6 pieces per minute). It is usually performed on swaging machines. There are many significant advantages of swaging, among them, e.g., possible high reduction of cross section at relatively low energetic costs, significantly dimensionally more precise forged pieces, higher surface quality and considerable improvement of mechanical properties of these products. This process has been known about for a relatively long time, which is also documented by many published studies. One of the main aims of these studies is to find a method of detection of pressure distribution on contact surface during individual deformations 
(Zhang, 1984). Individual approaches consider various assumptions related to the parameter of applied energy (Choi et al., 1997 and Canta et al., 1998) or to the course of metal flow (Standring et al., 1980) or (Wang et al., 2005).

Swaging can be divided into two main groups. The first group is hot swaging; the second one cold swaging. Both named groups are procedures characterized by high efficiency and they can be used both for the production of full bars and differently shaped pipes. Swaging is a process which can be described using gradual (incremental) deformations, and is widely applicable for the production of engineering parts such as disks, rings, gear shafts, etc. The main difference between cold and hot swaging is in the working temperature of the process and also the used lubrication (in cold swaging).

However, it is generally known that high-temperature swaging, when compared to the original state of SMA after homogenization, need not necessarily cause a significant difference in reached transformation temperatures. On the other hand, e.g., after cold rolling, there is a distinct (usually full) suppression of phase transformation. It should be noted however that even short annealing of such a deformed state will be enough to restore the memory effect. The annealing will unblock obstacles which prevent the mentioned transformation process and the transformation can proceed again. Although the values of transformation temperatures in the state after hot forming and in the original state are not very different, there are considerable differences in the structural arrangement. During forming, a distinct decrease in grain size occurs, which also determines the final mechanical properties of individual states. Based on the size and type of applied strain, this value after forming can be increased to twice the original value.

\subsection{Rolling}

During hot rolling, individual grains of SMA forming the structure are deformed and simultaneously recrystallized, which preserves their equiaxed microstructure. At the same time the deformation reinforcement is compensated. The source material is usually in the form of cast semiproducts such as plate slabs, bars or ingots, or semiproducts after forming (e.g., by previous swaging, etc.). Heating of SMA is usually performed in electric furnaces, since SMA semiproducts are generally of small dimensions. In contrast to swaging, there is not such a massive generation of deformation heat to maintain the working temperature of formed components or its slight increase. Although during rolling the temperature as a consequence of deformation changes depending on the deformation rate, it is not enough to compensate the heat loss to the environment or into the tools. That is why for most SMA products (semiproducts small in dimensions) there is a serious danger of going under the recrystallization temperature during the hot rolling itself. The temperature of formed semiproduct after rolling should be near the range from 50 to $100^{\circ} \mathrm{C}$ above the recrystallization temperature to ensure sufficient heat for the process. In the event of failure to comply with this condition, intermediate heating must be performed before the subsequent reduction. There are relatively many published experiments in the field of rolling focused on the effect of ausforming (forming in the region of austenite) or 
marforming (forming in the area of martensite). For example, the deformation behaviour of binary NiTi alloys during hot pressure or hot tensile tests is mapped (Dehghani \& Khamei, 2010 and Morakabati et al., 2010). Suzuki in (Suzuki et al., 1999) states that significant increase of hot formability can be achieved in NiTi alloys by forming at temperatures of $900^{\circ}$ $-1000^{\circ} \mathrm{C}$, but there is the drawback of the above mentioned surface oxidation.

When hot rolling is carried out, cold rolling usually follows. Cold rolling of SMA is a process which is much more difficult than the same hot process. The main factor that complicates this procedure is the absence of healing processes which are activated at increased temperatures. During cold rolling, in the course of deformation solidification of SMA takes place and consequently formability of materials decreases. Other influences include a higher value of deformation resistance when compared to hot rolling. Just as a consequence of the limited formability of SMA, microcracks may appear during cold rolling in rolled products. It should be stated that it can occur even at low reductions of height $(\sim 20 \%)$. In cases when the final wire is produced by cold rolling in calibres (with diameters usually lower than $5 \mathrm{~mm}$ ) the forming should take place in more stages. That is why a higher amount of passes is necessary to obtain the final wire. Probably the main reason for usage of cold rolling is to obtain dimensional accuracy and also the high surface quality of products prepared in this way. A side effect of cold forming (rolling) is suppression of the shape memory effect, while there is an increase of strength properties and a decrease of plastic properties.

With increasing content of $\mathrm{Ni}$, rolling is more and more difficult and when the limit of 51 at.\% of $\mathrm{Ni}$ is exceeded, any rolling of NiTi alloys is extremely difficult. The main reason is considerable deformation reinforcement. As is obvious from the more experimental results, yield strength of annealed NiTi alloys is usually lower than $100 \mathrm{MPa}$, but already after deformation of $40 \%$ this limit increases to values of about $1000 \mathrm{MPa}$. If the deformation continues, it would be very probable that cracks in the material would appear or even destruction of the material would take place. Intermediate annealing must therefore be performed before the next forming. This will cause a decrease of strength properties and a partial recovery of plastic properties. The just mentioned combination of deformationhealing (annealing) causes refinement of the final structure as a result. The temperature of intermediate annealing and its length will accordingly be the key parameters for the microstructure development. Generally it can be said that the temperature of intermediate annealing is lower than the temperature necessary for hot forming and usually is about $600^{\circ} \mathrm{C}(\mathrm{Wu}, 2002)$.

It is known that during cold forming (rolling) the increase of the volume fraction of martensite is much higher than during hot rolling. Relatively many experimental studies focused on thermomechanical processing of SMA and mapping the effects of rolling and subsequent annealing, e.g. (Kurita et al., 2004), confirm this knowledge. It can be briefly stated that the higher the annealing temperature is, the lower content of retained martensite you will find. However, this fraction can be present in SMA even at relatively high temperatures, which is also documented in numerous studies (Brailovski et al., 2006 and Lin 
$\& \mathrm{Wu}, 1994)$. The reason is the presence of dislocations which slow down its conversion to austenite during post deformation annealing. The potential softening during annealing can be considered in three ways (mechanisms): a) dislocation recovery after which retransformation of martensite to austenite takes place (at temperatures of about $400^{\circ} \mathrm{C}$ ), b) particle stimulated nucleation (PSN) at middle temperatures $\left.\left(\sim 500^{\circ} \mathrm{C}\right), \mathrm{c}\right)$ recrystallization of the matrix at high temperatures $\left(\sim 600^{\circ} \mathrm{C}\right)$. The needed level of deformation ensuring stable shape memory and superelastic behaviour of SMA (during cold rolling) is usually above 90\% (Kim et al., 2006).

Among other drawbacks of rolling, there is only a small possibility of controlling the grain morphology or texture at adequate refinement of the microstructure. These are substantial effects which can influence the shape memory characteristics. Generally it can be stated that in the case of the requirement to maximize the shape memory effect, the best solution is to use the NiTi alloy in the state after hot rolling. In the case of the requirement to obtain high strength and hardness at acceptable reversible deformation, the NiTi alloy should be used after cold rolling.

These were not the only reasons for the impulse for researching the effect of unconventional forming techniques on deformation behaviour, or transformation characteristics of SMA. Especially in recent times there is a significant effort during research regarding the application of Severe Plastic Deformations (SPD) in memory materials. Among other applied techniques within the group of SPD, there is e.g. High Pressure Torsion (HPT) technology, or the Equal Channel Angular Pressing (ECAP) process. It was already confirmed several times by experiments that these techniques are a very effective tool for influencing the transformation characteristics, cyclic stability SMA and simultaneously relatively easy control of the texture of these formed materials (Kockar et al., 2010).

\subsection{SPD processes}

As has already been stated, most of the characteristics of SMA are mainly based on reverse martensitic transformation, which is controlled by chemical composition, microstructural parameters and also the method of preparation. The possibility to control functional properties of materials based on Ni-Ti alloys using thermomechanical treatment can be improved through microstructural refinement, which is documented in many studies, e.g. (Sergueeva et al., 2003). It is most desirable to obtain the structure characterized by very small grain (subgrain) size - ultra fine grain (UFG) structure. Nevertheless, it is necessary to simultaneously preserve exceptional properties of memory alloys.

It is known that TiNi-based materials characterized by a very small grain size can be prepared via three methods. The first method is chilling of cast. The second one consists in the preparation using SPD methods and the third one is then the combination of conventional techniques and subsequent annealing. Using the first and the second method enables one to obtain a fine-grained structure with the grain size in the range of 200-600 $\mu \mathrm{m}$. If conventional forming with subsequent heat treatment will be used, then generally a larger grain size can be achieved compared to both of the previous variants. Nevertheless, a 
significant advantage of this method is obtaining a relatively equiaxed structure, although with a little larger grain size than in the case of SPD. A distinct difference between the conventional and unconventional method of forming is mainly in the intensity of applied strain. During conventional forming, only limited degrees of deformation can for technological reasons be applied on the formed material during one forming cycle. In addition to that - as has already been discussed above - this process should usually be performed at higher working temperature.

The principle of SPD processes is based on repeated application of high degrees of plastic deformation during individual forming cycles. This fact, together with relatively low applied temperature when these processes occur, is behind the structural refinement during SPD. The result of such deformations is equiaxed structures characterized by a relatively high amount of grains with high angle misorientation. In addition to these features, the structures can also be described by the presence of subgrains with high dislocation density (especially after ECAP). However, it must be noted that the materials prepared using SPD also contain areas with high internal stress, at least when compared to cast materials. In the case of HPT, it is possible to obtain even amorphous states which, after subsequent annealing, are transformed into nanostructural arrangements. Based on the selected regime, the final grain (subgrain) size can be expected then. The applied annealing of SMA is usually in the temperature range of $200 \div 400^{\circ} \mathrm{C}$. This is, at the same time, the interval of relatively stable grain size, nevertheless there is a significant decrease of dislocation density inside grains. With increasing temperature $\left(\sim 500^{\circ} \mathrm{C}\right)$ the grain size is increased to twice the original value, while grain boundaries are also much better defined. The reason of this increase is in the course of healing processes.

\subsubsection{High pressure torsion}

Localization of applied strain can thus be achieved using large plastic deformations. One of the first suggested and so far the most effective SPD method is the high pressure torsion process (HPT) (Fig. 8). It should be stated that in spite of certain limitations, deformation behaviour of a wide range of materials can be studied with this process. The consequence of the application of SPD is the destruction of the crystal lattice with subsequent transformation to the amorphous state. Accumulated dislocations or grain boundaries are the main driving force of the amorphization process. High density of dislocations may cause formation of amorphous bands thanks to shear deformation instability. In SMA, especially in NiTi-based alloys, a strong crystallographic texture is formed (Frick et al., 2004). In the following course of the process, refinement of grains and simultaneously amorphization are observed. This continues up to the full amorphous state of the formed material volume. According to this study and others, even the nanostructure formed like that contains characteristics of the texture, while in this state no directional deformation occurred. Individual nanograins exhibit preferred orientation which corresponds with orientation of nanograins preserved in the structure after HPT. A certain explanation may be knowledge assigning this influence to nanocrystals thanks to which heterogeneous nucleation occurs. 
It should be noted that such a structural state is stable only at low temperatures. For these reasons HPT is usually performed at room temperature or even lower. However, findings on the dependence between $\mathrm{M}_{\mathrm{s}}$ temperature and formation of nano-crystalline structure in SMA materials based on NiTi are very important. If the deformation temperature during SPD is lower than the corresponding $\mathrm{M}_{\mathrm{s}}$ temperature of the formed alloy, then there is a high probability of formation of nano-crystalline structure. If the deformation temperature is between the $\mathrm{M}_{\mathrm{s}}$ temperature and the highest temperature of the beginning of martensitic transformation influenced by deformation $(\mathrm{Md})$, then the probability of the nanostructure formation is lowered. If the deformation temperature is higher than the $\mathrm{M}_{\mathrm{d}}$ temperature, the probability of the nanostructure formation is very low. If after SPD post-deformation annealing is applied, then a submicrocrystalline structure is formed.

It was already mentioned that at specific temperature regimes set during annealing the alloy can crystallize into grains with the size $(10-40 \mathrm{~nm})$. The specific temperature range where NiTi alloys are stable is $250^{\circ}-300^{\circ} \mathrm{C}$ (Prokoshkin et al., 2005). With increasing temperature of annealing, the final nanostructure will be "coarser". Total amorphization of the structure is usually achievable only in cases when the deformation temperature is lower than the martensite start temperature $(\mathrm{Ms})$. Rate of the structure amorphization is influenced to large extent by the applied pressure during HPT. Higher imposed pressure suppresses the tendency to form an amorphous structure from nanostructure and as well to form nanostructure from deformably reinforced dislocation structure, as confirmed by the study (Prokoshkin et al., 2005). The probable reason is a decrease of $\mathrm{M}_{\mathrm{s}}$ temperature, due to higher values of pressure deformations.

Materials processed using HPT and subsequent heat treatments usually reach very high strength properties (strength higher than $2 \mathrm{GPa}$ ). Surprisingly, relatively high plastic characteristics are also preserved (elongation at break up to about $40 \%$ ) (Sergueeva et al., 2003). There are also assumptions to obtain super-plastic behaviour of NiTi alloys. Although the HPT technology appears to be a suitable candidate for positive modification of the properties, it is in principle excluded from commercial use by its main drawback (very small samples)-see Fig. 8b.

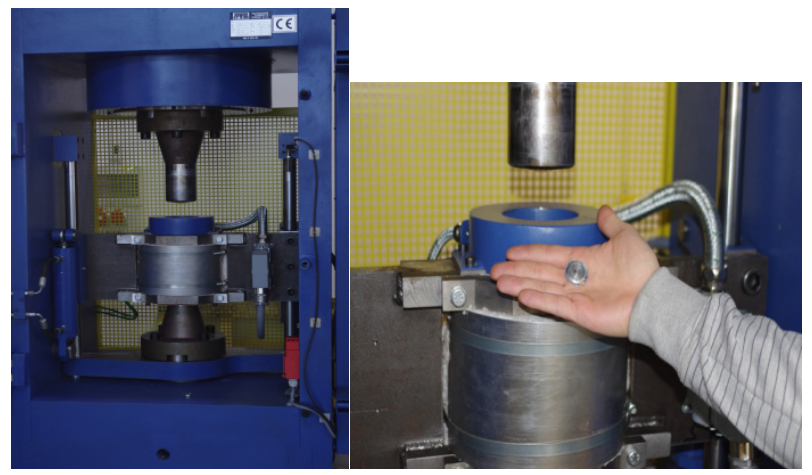

(a)

(b)

Figure 8. Machine for HPT process (a) detail of processed sample (b) 


\subsubsection{Equal channel angular pressing}

It was necessary to process larger volumes of products, which has led to looking for alternative ways of HPT substitution. One possible candidate for meeting the scheduled targets appears to be the equal channel angular pressing process (ECAP). In Fig. 9a you can see the assembly for practical application of this technique. It must be noted that, in contrast to HPT, various shapes of material sections can be processed here (Fig. 9b). As it was already mentioned, there is an effort when using SPD techniques to decrease the working temperature, because it is known that with decreasing deformation temperature the final grain size in the final structure of the treated material also decreases. Since SMA are characterized by a relatively high deformation resistance, the ECAP process - in contrast to HPT - should be performed at temperatures relatively higher. The most suitable range of forming temperatures found in experiments is $400^{\circ}-500^{\circ} \mathrm{C}$. Amorphization of the structure, however, cannot occur in this temperature interval. This fact also determines higher size of final grains when compared to HPT technique. The size of the grain is usually decreased to a value that lies in the region of $200-300 \mathrm{~nm}$. Although even in this case the strength properties are significantly increased while preserving relatively good plastic properties, these values are lower when compared with the state after HPT. Also the combination of ECAP and thermomechanical treatment is among tested procedures for another reduction of the grain size. To be more specific, cold rolling was applied after previous angular pressing (Pushin et al., 2006).

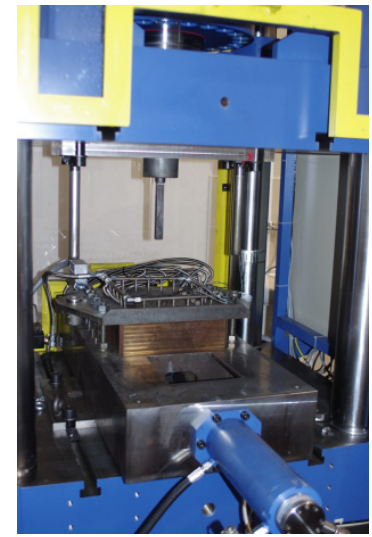

(a)

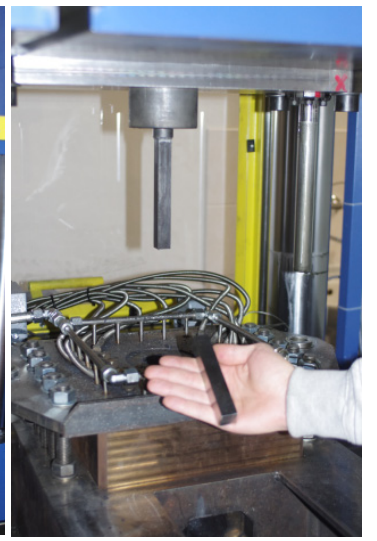

(b)

Figure 9. Machine for ECAP process (a) detail of assembly and processed sample (b)

NiTi alloys are very sensitive to the exact chemical composition, which is manifested even during their deformation using SPD techniques. For example, in the study (Khmelevskaya et al., 2001) the binary $\mathrm{Ni}_{50} \mathrm{Ti}_{50}$ alloy absolved 12 passes (ECAP) at the temperature $500^{\circ} \mathrm{C}$, or 8 passes at the temperature $400^{\circ} \mathrm{C}$; in the case of $\mathrm{Ni49.3Ti50.7}$ alloy, only 3 passes could be applied, since the material exhibited relatively low formability and it was destroyed. 
The reason for the formation of a fine-grained structure is probably the proceeding recrystallization process which causes gradual increase of disorientation of subgrain boundaries up to the formation of high-angle grain boundaries (HAGB). As to the ability of reversible deformation, its value after ECAP is comparable to the value obtained after application of conventional forming techniques (cold rolling) followed by heat treatment. It is documented, e.g., by the already mentioned study (Khmelevskaya et al., 2001) where the value of such deformation was determined to be $\sim 7 \%$. It should, however, be noted that the temperature interval of the memory effect after ECAP is narrower and also with lower values than after cold rolling. Similarly as after HPT, the temperature stability of SMA by annealing was tested up to temperatures of $500^{\circ} \mathrm{C}$. Similarly, also after ECAP, SMA appeared to be stable, but significant reduction of dislocation density occurred. Increasing temperature caused an increase of grain size.

Generally it is known that cooling of NiTi alloys below the $\mathrm{Ms}_{\mathrm{s}}$ temperature leads to higher formation of coarse-grained structure $(50 \div 80) \mu \mathrm{m}$ of the R phase. As confirmed by the study (Pushin \& Kondratjev, 1994), cooling of coarse-grained monocrystals of B2 NiTi alloys below the $\mathrm{Ms}_{\mathrm{s}}$ temperature leads to the formation of R-martensite with rhombohedral (or hexagonal) lattice. In the case of occurrence of other admixtures in binary and multiphase alloys, formation of monoclinic B19'martensite takes place during cooling below the $\mathrm{M}_{\mathrm{s}}$ temperature. In particular, occurrence of elements such as $\mathrm{Cu}, \mathrm{Pd}, \mathrm{Pt}$ or $\mathrm{Au}$ during cooling of the alloy below the $\mathrm{M}_{\mathrm{s}}$ temperature leads to formation of orthorhombic martensite B19 (Pushin, 2000). Generally it can be said that martensitic transformation on the microstructural level is caused by the presence of microtwins, while on the level of internal areas of grains it is caused by the formation of coherent crystals.

Martensitic phase transformation thus usually takes place from cubic B2 high-temperature phase (austenite) to monoclinic B 19' phase (martensite). This process is accompanied by high deformation. According to the results from the experiment (Waitz et al., 2004), if the grain size in SMA is in the region of nanometers, then the high density of grain boundaries will act as a significant obstacle during mentioned transformations. There are two main reasons why martensitic transformation in nanomaterials is suppressed. The decrease of transformation temperatures depending on the decrease of grain size follows from the mentioned study. It was also proved that full suppression of martensitic transformation takes place when the grain size is smaller than $50 \mathrm{~nm}$. From the point of view of phase stability, these small grains have a significant influence on morphology of martensite (Waltz, 2005).

Thanks to the experiment performed with the Ni50.4Ti alloy, the specific influence of forming on transformation characteristics and also on microstructure development was mapped. The experiment describes the problem of combination of conventional forming techniques together with unconventional ones. For forming, SMA characterized by the content of $\mathrm{O}_{2}\left(0.0624\right.$ wt.\%) and $\mathrm{N}_{2}(0.0039$ wt.\%) was used. The content of carbon $(0.055$ at.\%) was determined using spectrometry. The diameter of the cast was $20 \mathrm{~mm}$ and the cast length $350 \mathrm{~mm}$. Then homogenization at the temperature of $850^{\circ} \mathrm{C}$ is followed by subsequent cooling. 
The forming itself was suggested in the first phase using swaging then pressing using the ECAP technique was performed. Swaging was performed at the temperature of $850^{\circ} \mathrm{C}$. During swaging, the strain was applied gradually in individual reductions. The total strain applied on the cross section was $66 \%$. On the contrary, the ECAP technology was applied on SMA at the temperature of $290^{\circ} \mathrm{C}$. Because of possible "negative" influence on the temperature fluctuation of the formed material, the pressed samples were placed in the steel "cans". For the ECAP, matrix with the angle $105^{\circ}$ between individual canals was used; the extrusion speed was set to $1 \mathrm{~mm} / \mathrm{s}$. The extrusion itself consisted of two performed passes, where Bc was chosen as the deformation path. In particular, the influence of intensities of applied strain in relation to mechanical and thermophysical properties and the course of healing processes were studied. To be able to determine the mentioned effect, heat treatment was carried out after the performed deformation. In addition to optical microscopy, RTG diffraction was also used for evaluation of changes. The differences between after swaging followed by ECAP are obvious from the attached photos (Fig. 10).

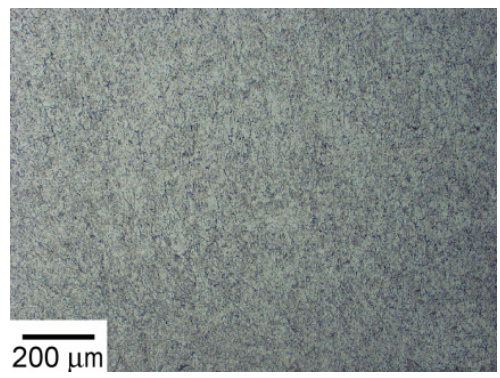

(a)

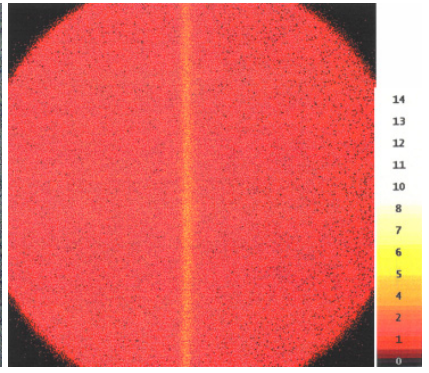

(b)

Figure 10. Ni50.4Ti alloy (swaged+ECAPed) : microstructure (a), diffraction fringe (b)

To be able to specify the differences caused by applied strain, it was necessary to perform heat treatment of the deformed materials. These annealing using selected temperature regimes $\left(550^{\circ} \mathrm{C} / 15 \mathrm{~min}, 600^{\circ} \mathrm{C} / 15 \mathrm{~min}, 650^{\circ} \mathrm{C} / 15 \mathrm{~min}, 900^{\circ} \mathrm{C} / 15 \mathrm{~min}\right.$ ) should provide information on the influence of the accumulated deformation on the beginning of corresponding processes, especially recrystallization.

The azimuthal profile of diffraction lines of the NiTi alloy confirms that all mosaic blocks (DCA-diffraction coherent areas of crystallites) in the structure after ECAP are smaller than $10 \mu \mathrm{m}$ (Fig. 10b). The DCA are regions that scatter coherently. These areas are defined by borders where is high dislocation density. Within the framework of the mosaic blocks, the moving dislocations face minimal resistance. Inside the mosaic blocks is much less of dislocations than on the borders of blocks, that is why the mosaic blocks are called as dislocationless cells (areas) in the crystallites. Nevertheless, this predication is not quite accurate because one of obstacle in these blocks for dislocation movement is Peierls Nabarro stress (i.e. dislocation is moving through the mosaic block, so that mosaic block must have at least one dislocation). This labeling (dislocationless blocks) is commonly used, important factor is that inside of the mosaic blocks is considerably less of dislocation than on 
its boundaries. Due to this matter (low dislocation density inside of mosaic block) can X-ray be diffracted coherently (that is why the mosaic blocks are also often marked as Coherent Scattering Regions - CSR's). The presence of blocks smaller then $10 \mu \mathrm{m}$ was confirmed by XRD. Generally may be noticed that mosaic blocks (obtained by XRD) are not the same as grains observed by optical microscopy. Mosaic blocks can be seen by presence of reflections on XRD patterns. In the case of the large block presence will be its reflection large as well. Since cannot into the diffracted volume be much of big mosaic blocks present, there will be their reflections on diffraction lines clearly separated. If will be mosaic block small there will be much of their reflections in diffracted volume. That is why individual reflection are overlapping (they are not separated i.e. reflection is continuous). More detailed information about this technique can be found for example in (Hindelah \& Hosemann, 1988).

As a consequence of recrystallization processes after annealing of the extruded alloy at temperatures of $600^{\circ} \mathrm{C}$ and higher in the structure blocks larger than $10 \mu \mathrm{m}$ were formed, while after the same length of time annealing at lower temperatures all mosaic blocks remained smaller than $10 \mu \mathrm{m}$. It should be noted that the size distribution of mosaic blocks was bimodal (i.e. blocks larger than $10 \mu \mathrm{m}$ and blocks smaller than $10 \mu \mathrm{m}$ ). This means that coarser crystallites contain more nickel than smaller crystals. The reason is the asymmetry of the area in the phase diagram of titanium - nickel formed by a solid solution of TiNi. Microinhomogeneity of the alloy also influences mechanical properties of the alloy. The dispersion of such elementary composition and thus lattice parameters of individual mosaic blocks in the structure causes so-called microstrain (strain of the $2^{\text {nd }}$ order) influencing the dynamics of dislocations, but also nucleation and growth of microcracks. These strains of the $2^{\text {nd }}$ order also influence shifts of walls of mosaic blocks and thus the course of recrystallization of the alloy. The authors of the experiment performed with the Ni50.6Ti alloy also arrived at similar results (Kocich et al., 2009).

It means that even with very thoroughly conducted preparation of material based on shape memory alloys, microinhomogeneities may be formed. As concerns the forming technologies as such, it can be stated that after completed rotary forging (swaging) the initial grain size and therefore also the ensuing properties were substantially changed. The ECAP process also proved its influence on the final appearance of the micro- and substructure. The differences are even apparent in the number of passes; if material passed through the matrix only once, then no mosaic blocks smaller than $10 \mu \mathrm{m}$ occurred in the structure, however, influence of the second pass can be seen here, when the samples of the NiTi alloy already contained bi-modal composition. The temperature that appeared to be the starting temperature for initiation of re-crystallisation was $600^{\circ} \mathrm{C}$.

\section{Conclusions}

For some specific purposes, the exclusivity of binary shape memory alloys should be modified by the addition of another element. These prepared Ti-Ni- $\mathrm{X}$ based materials are currently very progressive materials. As has already been indicated, their final properties will, to a great extent, be determined by the chosen element. To a great extent, it is thus the 
factor of chemical composition; nevertheless that is not the only one. A significant influence in the sense of the effect on transformation characteristics together with other properties was also demonstrated for the preparation method. There is an outstanding dependence on used forming technology and their relationship or thermomechanical conditions play an important role. During conventional forming, the deformation behaviour of SMA binary systems is relatively well known. As seems to be the case, multiphase SMA are very sensitive to even small deviations from the required chemical composition. These nuances can be observed through the shifts in recrystallization temperatures, which also means the shifts in their optimum forming temperatures.

Particularly at this time there is intensive research of use of unconventional forming techniques for SMA. Although it is already known that when using these procedures, in contrast to conventional forming, it is possible to obtain structures characterized by grain size of nanometers, the procedure is currently not optimized for practical applications. The effectiveness of procedures based on applications of large plastic deformations consists mainly in a distinct decrease of grain size. There is also an obvious benefit in controlled textures of deformed SMA, which can also be utilized with regard to required final properties.

Although studies monitoring behaviour of multiphase Ti-Ni-X based systems exist, a generally known method for the preparation of SMA is not still available. In the future there should be actions related to preparation of specific alloys with verified behaviour. It is obvious that hand-in-hand with the above mentioned there should also be development focused on the preparation and target modification of properties of these materials.

\section{Author details}

Radim Kocich, Ivo Szurman and Miroslav Kursa

VŠB Technical University of Ostrava, Czech Republic

\section{Acknowledgement}

This paper was created under the project No. CZ.1.05/2.1.00/01.0040 "Regional Materials Science and Technology Centre" within the frame of the operation programme "Research and Development for Innovations" financed by the Structural Funds and from the state budget of the Czech Republic and project GA 106/09/1573 "Optimisation of chemical composition, structural characteristics, mechanical properties of NiTi alloys for biomechanical applications".

\section{References}

Bertheville, B.; Bidaux, J.E. (2005). Alternative powder metallurgical processing of Ti-rich NiTi shape memory alloys, Scripta Materialia, Vol.52, pp. 507-512, ISSN 1359-6462 
Bertolino, N.; Monagheddu, M.; Tacca, A.; Giuliani, P.; Zanotti, C.; Tamburini, A.U. (2003). Ignition mechanism in combustion synthesis of $\mathrm{Ti}-\mathrm{Al}$ and $\mathrm{Ti}-\mathrm{Ni}$ systems, Intermetallics, Vol.11, pp. 41-46, ISSN 0966-9795

Brailovski, V.; Prokoshkin, S.D.; Khmelevskaya, I.Y.; Inaekyan, K.E.; Demers, V.; Dobatkin, S.V.; Tatyanin, E.V. (2006). Structure and properties of the Ti-50.0 at $\% \mathrm{Ni}$ alloy after strain hardening and nanocrystallizing thermomechanical processing, Materials Transactions, Vol.47, pp. 795-802, ISSN 1347-5320

Canta, T.; Frunza, D.; Sabadus, D.; Tintelecan, C. (1998). Some aspects of energy distribution in rotary forming processes, Journal of Material Processing and Technology, Vol.80-81, pp. 195-201, ISSN 0924-0136

Choi, S.; Nam, K.H.; Kim, J.H. (1997). Upper-bound analysis of the rotary forging of a cylindrical bilet, Journal of Material Processing and Technology, Vol.67, pp. 78-84, ISSN 0924-0136

Choi, M.S.; Fukuda, T.; Kakeshita, T. (2005). Anomalies in resistivity, magnetic susceptibility and specific heat in iron-doped Ti-Ni shape memory alloys, Scripta Materialia, Vol. 53, pp. 869-873, ISSN 1359-6462

Dautovich, D.P.; Purdy, G.R. (1965). Phase Transformations in TiNi, Canadian Metallurgical Quarterly, Vol.4, pp. 129-134, ISSN 1879-1395

Dehghani, K.; Khamei, A.A. (2010). Hot deformation behavior of $60 \mathrm{Nitinol}$ (Ni60 wt\%- Ti40 wt.\%) alloy: experimental and computational studies, Materials Science and Engineering A, Vol.527, pp.684-690, ISSN 0921-509

Dembovský, V. (1978). Plasma metallurgy, SNTL, Praha (in Czech) ISBN 04-407-78

Dembovský, V. (1985). Plasma metallurgy: The principles, SNTL, Praha, ISBN 0-444-99603-6

Du, Y.; Schuster, J.C. (1998). Experimental investigation and thermodynamic modeling of the Ni-Ti-C system, Zeitschrift fur Metallkunde, Vol.89, pp. 399-410, ISSN 1862-5282

Duerig, T.W.; Pelton, A.; Stöckel, D. (1999). An overview of nitinol medical applications, Materials Science and Engineering A, Vol.273-275, pp.149-160, ISSN 0921-5093

Frenzel, J.; Zhang, Z.; Neuking, K.; Eggeler, G. (2004). High quality vacuum induction melting of small quantities of NiTi shape memory alloys in graphite crucibles, Journal of Alloys and Compounds, Vol.385, pp. 214-221, ISSN 0925-8388

Frenzel, J.; Zhang, Z.; Somsen, Ch.; Neuking, K.; Eggeler, G. (2007a). Influence of carbon on martensitic phase transformations in NiTi shape memory alloys, Acta Materialia Vol.55, pp. 1331-1339. ISSN 1359-6454

Frenzel, J.; Pfetzing, J.; Neuking, K.; Eggeler, G. (2007b). On the influence of thermomechanical treatments on the microstructure and phase transformation behavior of Ni-Ti-Fe shape memory alloys, Materials Science and Engineering A, Vol.481-482, pp. 635-642, ISSN 0921-509

Frick, C.; Ortega, A.; Tyber, J.; Gall, K.; Maier, H. (2004). Multiscale structure and properties of cast and deformation processed polycrystalline NiTi shape-memory alloys, Metallurgical and Material Transactions A, Vol.35, pp. 2013-2021, ISSN 1073-5623

Gili, F.J.; Solano, E.; Penal, J.; Engel, E.; Mendoza, A.; Planell, J.A. (2004). Microstructural, mechanical and cytotoxicity evaluation of different NiTi and NiTiCu shape memory alloys, Journal of Material Science, Vol.15, pp. 1181-1189, ISSN 0022-2461 
Graham, R. (2004). Characteristics of high purity nitinol in Shape Memory and Superelastic Technologies. Proceedings of conferece SMST Society Inc., Denver, 16-19.4.2004, pp. 7-12

Hindelah, A.M.; Hosemann R. (1988) Paracrystals representing the physical state of matter, Journal of Physics C: Solid State Physics Vol.21, pp. 4155-4162, ISSN 0022-3719

Jung, J.; Ghosh, G.; Isheim, D.; Olson, G.B. (2003). Design of nanodispersion strengthened TiNi-base shape memory alloys, Proceedings of the international conference on Shape memory and superelastic technologies- SMST 2003, ISBN 0-9660508, pp. 45-50.

Khmelevskaya, I.; Trubitsyna, I.B.; Prokoshkin, S.D.; Dobatkin, S.V.; Stolyarov, V.V.; Prokofjev, E.A. (2001). Structure and Functional Properties of Ti-Ni-Based Shape Memory Alloys Subjected to Severe Plastic deformation, Nanomaterials by Severe Plastic Deformation, pp. 170-176, Wiley-VCH, Weinheim, Germany, ISBN 3527306595

Kim, H.Y.; Ikehara, Y.; Kim, J.I.; Hosoda, H.; Miyazaki, S. (2006). Martensitic transformation, shape memory effect and superelasticity of Ti-Nb binary alloys, Acta Materialia, Vol.54, pp. 2419-2425, ISSN 1359-6454

Kocich, R.; Kursa, M.; Greger, M.; Szurman, I. (2007). Deformation behavior of shape memory alloys on ECAP process, Acta Metallurgica Slovaca, Vol. 13, pp. 570-576, ISSN 1338-1156

Kocich, R.; Szurman, I.; Kursa, M.; Fiala, J. Investigation of influence of preparation and heat treatment on deformation behaviour of the alloy NiTi after ECAE, Materials Science and Engineering A, Vol.512, pp. 100-104, ISSN 0921-5093

Kockar, B.; Atli, K.C.; Ma, J.; Haouaoui, M.; Karaman, I.; Nagasako, M.; Kainuma, R. (2010). Role of severe plastic deformation on the cyclic reversibility of a Ti50.3Ni33.7Pd16 high temperature shape memory alloy, Acta Materialia, Vol.58, pp. 6411-6417, ISSN 1359-6454

Kuchař, L.; Drápala, J. (2000). Metallurgy of pure metals-methods of pure materials purifying, Košice Press. ISBN 80-7099-471-1

Kurita, T.; Matsumoto, H.; Abe, H. (2004). Transformation behavior in rolled NiTi, Journal of Alloys and Compounds, Vol.381, pp. 158-166, ISSN 0925-8388

Kursa, M.; Szurman, I.; Drápala, J.; Losertová, M.; Greger, M. (2005). Shape memory materials $\mathrm{Ni}$-Ti-Me and possibilities of control of their transformation characteristics, VŠB-TU Ostrava (ed), ISBN80-248-0894-3, pp. 23-46

Lin, H.C.; Wu, S.K. (1994). The tensile behavior of a cold-rolled and reverse-transformed equiatomic TiNi alloy, Acta Metallurgica Materialia, Vol.42, pp. 1623-1631, ISSN 13596454

Liu, Y. (2003). Mechanical and thermomechanical properties of a $\mathrm{Ti}_{50} \mathrm{Ni}_{25} \mathrm{Cu}_{25}$ melt spun ribbon, Materials Science and Engineering A, Vol.354, pp. 286-290, ISSN 0921-509

Liu, X.; Wang, Y.; Yang, D.; Qi, M. (2008). The effect of ageing treatment on shape-setting and superelasticity of a NiTi stent, Materials Characterization Vol.59, pp. 402-408, ISSN 1044-5803

Locci, A.M.; Orrù, R.; Cao, G.; Munir Z.A. (2003). Field-activated pressure-assisted synthesis of NiTi, Intermetallics, Vol.11, pp. 555-571, ISSN 0966-9795

$\mathrm{Ma}$, j.l.; Wu, k.h. (2000). Effects of Tantalum addition on transformation behaviour of (Ni51 Ti49 )1-x Tax and Nis0 Tiso-y Tay Shape Memory Alloys, Materials Science and Technology, Vol.16, pp. 716-719, ISSN 1743-2847 
Meng, X.L.; Cai, W.; Wang, L.M.; Zheng, Y.F.; Zhao, L.C.; Zhou, L.M. (2001). Microstructure of Stress-Induced Martensite in a Ti-Ni-Hf High. Temperature Shape Memory Alloy, Scripta Materialia, Vol.45, pp.1177-1182, ISSN 1359-6462

Mentz, J.; Bram, M.; Buchkremer, H.P.; Stöver, D. (2006). Improvement of Mechanical Properties of Powder Metallurgical NiTi Shape Memory Alloys, Advanced Engineering Materials, Vol.8, pp. 247-252, ISSN 1527-2648

Mentz, J.; Frenzel, J.; Wagner, M.F.X.; Neuking, K.; Eggeler, G; Buchkremer, H.P.; Stöver, D. (2008). Powder metallurgical processing of NiTi shape memory alloys with elevated transformation temperatures, Materials Science and Engineering A, Vol.491, pp. 270-278, ISSN 0921-5093

Morakabati, M.; Kheirandish, S.; Aboutalebi, M.; Karimi-Taheri, A.; Abbasi, S.M. (2010). The effect of $\mathrm{Cu}$ addition on the hot deformation behavior of NiTi shape memory Alloys, Journal of Alloys and Compounds, Vol.499, pp. 57-66, ISSN 0925-8388

Morgiel, J.; Cesari, E.; Pons, J.; Pasko, A.; Dutkiewicz, J. (2002). Microstructure and martensite transformation in aged $\mathrm{Ti}-25 \mathrm{Ni}-25 \mathrm{Cu}$ shape memory melt spun ribbons, Journal of Material Science, Vol.37, pp. 5319-5327, ISSN 0022-2461

Mousavi, T.; Karimzadeh, F.; Abbasi, M.H. (2008). Synthesis and characterization of nanocrystalline NiTi intermetallic by mechanical alloying, Materials Science and Engineering A, Vol.487, pp. 46-51, ISSN 1527-2648

Nam, T.H.; Saburi, T.; Shimizu, K. (1990). Shape memory characteristics associated with the $\mathrm{B} 2 \leftrightarrow \mathrm{B} 19$ and $\mathrm{B} 19 \leftrightarrow \mathrm{B} 19^{\prime}$ transformations in a Ti-40Ni-10Cu (at.\%) alloy, Materials Transactions JIM Vol.31, pp. 959-968, ISSN 1073-5623

Noh, J.P. (2001). Phase transformation behaviours and shape memory characteristics of Ti(45-x)Ni-5Cu-xMo (x=0-3-1.0) alloys, Materials Science and Technology, Vol.17, pp. 15441550, ISSN 1743-2847

Otsuka, K.; Wayman, C.M. (Eds). (1998). Shape Memory Materials, Cambridge University Press, ISBN 052144487X

Pacholek, P.; Szurman, I.; Sklenaříková, I.; Kursa, M. (2003). Preparation specificity of shape memory alloys on the base of NiTi, Proceedings of $8^{\text {th }}$ International conference Technology 2003, ISBN 80-227-1935-8, Bratislava, 5. - 7.9. 2003, pp. 38-42

Prokoshkin, S.D.; Khmelevskaya, I.Y.; Dobatkin, S.B.; Trubitsyna, I.B.; Tatyanin, E.V.; Stolyarov, V.V.; Prokofiev, E.A. (2005). Alloy composition, deformation temperature, pressure and post-deformation annealing effects in severely deformed $\mathrm{Ti}-\mathrm{Ni}$ based shape memory alloys, Acta Materialia, Vol.53, pp. 2703-2710, ISSN 1359-6454

Pushin, V.G.; Kondratjev, V.V. (1994). Processing of nanostructured TiNi-shape memory alloys: Methods, structures, properties, application, Physics of Metals and Metallography, Vol.7, pp. 497-501, ISSN 1555-6190

Pushin, V.G. (2000). Alloys with a Thermomechanical Memory: Structure, Properties, and Application, Physics of Metals and Metallography, Vol.S68-S95, pp. 90-96, ISSN 1555-6190

Pushin, V.G.; Valiev, R.Z.; Zhu, Y.T.; Prokoshkin, S.D.; Gunderov, D.V.; Yurchenko, L.I. (2006). Effect of Equal Channel Angular Pressing and Repeated Rolling on Structure, Phase Transformations and Properties of TiNi Shape Memory Alloys, Materials Science Forum, Vol.503-504, pp. 539-540, ISSN 0255-5476 
Ramaiah, K.V. (2005). Processing of Ni-Ti Shape Memory Alloys, Proceedings of conference Smart materials structures and systems, Bangalore, 4-6.5. 2005, pp. 23-30.

Raz, S.B.; Sadrnezhaad, S.K. (2004). Effect of VIM frequency on chemical composition, homogeneity and microstructure of NiTi shape memory alloy, Materials Science and Technology, Vol.20, pp. 593-598, ISSN 1743-2847

Sakuma, T.; Iwata, I.; Okita, K. (2003). Effect of additional elements on erosion and wear characteristics of Ti-Ni shape memory alloy, Corrosion Engineering, Science and Techology, Vol.52, pp. 821-832, ISSN 1743-2782

Schetky, L.; Wu, M.H. (2005). Issues in the further Development of Nitinol Properties and Processing for medical Device Applications, Memry Corporation. 18.10.2010, Available from http//memry.com/technology/pdfs/ASM03_NitinolDevelop.pdf

Sergueeva, A.V.; Song, C.; Valiev, R.Z.; Mukherjee, A.K. (2003). Structure and properties of amorphous and nanocrystalline NiTi prepared by severe plastic deformation and annealing, Materials Science and Engineering A, Vol.339, pp. 159-165, ISSN 0921-509

Standring, P.M.; Moon, J.R.; Appleton, E. (1980). Plastic deformation produced during indentation phase of rotary forging, Journal of Material Processing and Technology, Vol.7, pp. 159-167, ISSN 0924-0136

Suzuki, H.G.; Takakura, E.; Eylon, D. (1999). Hot strength and hot ductility of titanium alloys-a challenge for continuous casting process, Materials Science and Engineering A, Vol.263, pp. 230-236, ISSN 0921-509

Szurman, I.; Kursa, M. (2009). Processing technologies of Ni-Ti based shape memory alloys. Proceedings of $8^{\text {th }}$ European Symposium on Martensitic Transformations, ISBN 978-2-75980480-1 Prague, 7-11. 9. 2009, pp. 75-81

Szurman, I.; Kursa, M. (2010). Methods for Ni-Ti based alloys preparation and their comparison. Proceedings of conference Metal 2010, ISBN 978-80-87294-17-8, Rožnov pod Radhoštěm, 18. - 20.5. 2010, pp. 861-866

Tang, W.; Sandstro M, R.; Wei, Z.G.; S. Miyazaki. (2000). Experimental investigation and thermodynamic calculation of the TiNiCu shape memory alloys, Metallurgical and Material Transactions A, Vol.31, pp. 2423-2429, ISSN 1073-5623

Tsai, J.Ch.; Jean, R.D. (1994). Effects of hot working on the martensitic transformation of NiTi alloy, Scripta Metallurgica et Materialia, Vol.30, pp. 1027-1030, ISSN 1359-6462

Van Humbeeck, J.V. (2001). Shape memory alloys: A material and technology. Advanced Engineering Materials, Vol.3, pp. 837-850, ISSNXXX 1527-2648

Waitz, T.; Kazykhanov, V.; Karnthaler, H.P. (2004). Martensitic phase transformations in nanocrystalline NiTi studied by TEM, Acta Materialia, Vol.52, pp. 137-143, ISSN 13596454

Waitz, T. (2005). The self-accommodated morphology of martensite in nanocrystalline NiTi shape memory alloys, Acta Materialia, Vol.53, pp. 2273-2280, ISSN 1359-6454

Wang, G.C.; Guan, J.; Zhao, G.Q. (2005). A photo-plastic experimental study on deformation of rotary forging a ring workpiece. Journal of Material Processing and Technology, Vol.169, pp. 108-115, ISSN 0924-0136

Wu, M.H. (2001). Fabrication of Nitinol materials and components, Proceedings of conference SMST -SMM 2001, ISBN 978-0-87849-896-3, pp. 285-291 
Wu, M.H. (2002). Fabrication of Nitinol Materials and Components, Materials Science Forum, Vol. 394-395, pp. 284-290, ISSN 0255-5476

Zhang, M. (1984). Calculating force and energy during rotary forging, in proceedings of conference on rotary metal working processes, Journal of Material Processing and Technology, Vol.7, pp. 115-124, ISSN 0924-0136

Zhang, Z.; Frenzel, J.; Neuking, K.; Eggeler, G. (2005). On the reaction between NiTi melts and crucible graphite during vacuum induction melting of NiTi shape memory alloys, Acta Materiala, Vol.53, pp. 3971-3978, ISSN 1359-6454

Zhang, Z.; Frenzel, J.; Neuking, K.; Eggeler, G. (2006). Vacuum induction melting of ternary NiTiX $(X=\mathrm{Cu}, \mathrm{De}, \mathrm{Hf}, \mathrm{Zr})$ shape memory alloys using graphite crucibles, Materials Transactions A, Vol.47, pp. 661-665, ISSN 1073-5623

Zhu, S.L.; Yang, X.J.; Fu, D.H.; Zhang, L.Y.; Li, C.Y.; Cui, Z.D. (2005). Stress-strain behavior of porous NiTi alloys prepared by powders sintering, Materials Science and Engineering A, Vol.408, pp. 264-268, ISSN 0921-509 